Revista Española de

In vest ig a c i ón

Criminológic a

\title{
El control de espacios públicos como técnica de exclusión social. Algunos contrastes regionales.
}

\section{Control of public places as a social exclusion technique. Some regional contrasts.}

Recibido el 1 octubre 2014/Publicado el 31 octubre 2014

\author{
José Luis Díez Ripollés ${ }^{1}$ \\ Universidad de Málaga
}

\begin{abstract}
RESUMEN
La ciudad como espacio privilegiado de interacción y cooperación sociales, en la que se facilita la relación entre desconocidos, está experimentando una notable transformación. Esa reorganización incide singularmente sobre personas y colectivos tradicionalmente sospechosos, en los que acentúa su exclusión social. El estudio analiza varias técnicas de desplazamiento de esas personas y colectivos de los espacios públicos ciudadanos, en concreto: las urbanizaciones cerradas y el aburguesamiento de barrios, el empleo de videocámaras en lugares públicos y privados de acceso público, y las prohibiciones de acceso de ciertas personas a determinados espacios ciudadanos. El trabajo pretende confrontar tales prácticas en dos áreas geográficas con marcadas diferencias en la práctica del control social, Estados Unidos de América y los países nórdicos europeos.
\end{abstract}

Palabras clave: Exclusión social, control de espacios públicos, urbanizaciones cerradas, aburguesamiento, videocámaras, prohibiciones de acceso, política criminal comparada.

\footnotetext{
${ }^{1}$ La correspondencia debe enviarse a: José Luis Díez Ripollés. Facultad de Derecho. Universidad de Málaga. Bulevar Louis Pasteur. Campus de Teatinos. 29071 Málaga. España. ripolles@uma.es
} 


\begin{abstract}
Cities as privileged spaces for social interaction and cooperation, where easy relations occur among residents, are experiencing a profound transformation. This reconfiguration affects mainly to traditionally suspected persons and groups, whose social exclusion is strengthened. The study targets a number of techniques, which displace these persons and groups from city public spaces, such us: gated communities and gentrification, employment of CCTV techniques in public places and in private places with public access, and off-limits, exclusion and no-trespass orders. The paper intends to confront such practices in two geographical areas with significant differences in the enforcement of social control, the United States of America and the European Nordic countries.
\end{abstract}

Keywords: Social exclusion, control of public spaces, gated communities, gentrification, CCTV, banishment, comparative criminal justice policy.

\title{
1. La transformación de la ciudad.
}

La ciudad se ha considerado desde antiguo como lugar privilegiado de interacción social, y no es por azar que términos tan relevantes para nuestra convivencia como civilización o ciudadanía, entre otros, deriven etimológicamente de ese término. La ciudad ha constituido el espacio en el que los seres humanos han podido desarrollar plenamente sus capacidades comunicativas y donde han podido beneficiarse de los efectos de la cooperación social. Sus diversas configuraciones históricas dicen mucho sobre la cultura de la época, pues los espacios ciudadanos pueden diseñarse de acuerdo a un amplio espectro de posibilidades.

La estructura ciudadana puede ser una que facilite la relación con extraños, las interacciones entre desconocidos en ella residentes. Se potencia de este modo la capacidad de la ciudad para generar un sentimiento de pertenencia a un mismo colectivo $\mathrm{y}$, consecuentemente, para aprovechar las cualidades de cada uno de sus integrantes a la hora de llevar a cabo tareas comunes mutuamente beneficiosas. Eso supone que la ciudad se organiza de manera que incentiva o al menos no obstaculiza relaciones continuas, ocasionales o persistentes, entre todos sus ciudadanos; que procura que ningún ciudadano o colectivo con independencia de sus condiciones personales o sociales, y a salvo el mantenimiento de una convivencia pacífica, se vea excluido de las 
atrayentes posibilidades de autorrealización personal que la ciudad ofrece; y que aprovecha las sinergias colectivas derivadas de la cooperación social.

Sin embargo, la ciudad puede también organizar sus espacios de un modo que, sin renunciar a ser la catalizadora de la convivencia social, fomente determinadas interacciones sociales en detrimento de otras, y excluya o limite a ciertos ciudadanos o grupos el acceso o la participación en algunas de esas actividades sociales. La ciudad, entonces, compatibiliza su función integradora con otra segregadora o diferenciadora. Se convierte así en un instrumento discriminante de las interacciones sociales, y entorpecedor de los sentimientos de pertenencia colectiva. Desaprovecha, en fin, los beneficios derivados de la integración social del conjunto de los ciudadanos (Baumann, 2006; Young, 2003).

En este sentido, es cada vez más frecuente que nuestras ciudades del mundo desarrollado modelen determinados espacios urbanos de un modo que excluyen tanto interacciones sociales distintas a las asignadas específicamente para ese lugar como incluso la presencia de ciudadanos con apariencia o comportamiento diversos a los deseados en ese ámbito: Se provee a zonas destinadas predominantemente al consumo de bienes y mercancías de instrumentos para desanimar el acceso a esos lugares de ciudadanos no consumidores, o de ciudadanos que pueden desincentivar la actividad comercial de los consumidores. Áreas con especiales cualidades para atraer el turismo son dotadas de los medios precisos para que aquellos ciudadanos cuya apariencia no corresponde con la imagen que se quiere transmitir, o que disfrutan parasitariamente de ese espacio, tengan dificultades para permanecer en ellas. En los distritos financieros se impide la presencia de personas que difícilmente van a poder trabajar en esa rama profesional, o utilizar esos servicios, para evitar contrastes incómodos en la actividad cotidiana. Barrios residenciales con un nivel económico alto o medio se estructuran de manera que se obstaculice el acceso irrestricto de quienes no alcancen ese nivel, previniendo así malestar o inquietud entre los residentes.

No parece exagerado afirmar que existe en el mundo desarrollado una progresiva renuncia a configurar las ciudades como lugares de interacción social de todos sus ciudadanos. Un número cada vez mayor de lugares públicos, como aeropuertos, estaciones, vías rápidas, plazas, parques, entre otros, se diseña específicamente para entorpecer la interacción social o hacerla muy superficial, y se le dota del mobiliario 
correspondiente: grandes espacios a recorrer con medios mecánicos, bancos incómodos o ausentes, carencia de aceras, lugares diáfanos poco acogedores, ausencia de aseos callejeros, etc. Estos y otros lugares públicos están controlados mediante videocámaras o sometidos a controles de acceso. Espacios antes públicos, como calles comerciales, estaciones de transporte, centros prestadores de servicios generales adoptan el régimen propio de los lugares privados de acceso público. Estos últimos están plagados de videocámaras, barreras de acceso, vigilantes privados... Las clases acomodadas colonizan viejas zonas residenciales, antes habitadas por ciudadanos con menor renta, lo que origina el aburguesamiento de esos barrios y fuerza a los antiguos residentes a abandonarlos al no poder afrontar las nuevas condiciones socioeconómicas. Vivir en una urbanización cerrada, que impida mediante obstáculos físicos el acceso sin autorización de los no residentes, y provista del mayor número de servicios dentro de ella, constituye cada vez más un signo de alto estatus social en la medida que reduce las interacciones sociales interclasistas (Beckett y Herbert, 2008; Beckett y Herbert 2010; Cerezo Domínguez y Díez Ripollés, 2011; Coleman y Sim, 2005; Doherty, BuschGeertsema, Karpuskiene et al., 2008; Lynch, 2001; Medina, 2011; Midtveit, 2005; Mork Lomell, 2004; Rudinow Soetnan, Mork Lomell y Wiecek, 2004).

La criminología no se ha mantenido ajena a esta evolución y ha suministrado técnicas relevantes para su consolidación: desde los más conspicuos enfoques de prevención situacional, centrados de modo especial en eliminar las oportunidades delictivas, hasta las propuestas de prevención del delito mediante el diseño ambiental CPTED-, más integradas en un enfoque de prevención comunitaria y de reforzamiento de los lazos de apego al territorio y espacio urbanos (Medina, 2011; Vozmediano y San Juan 2010).

Las causas de esta transformación urbana son variadas y solo podemos ahora apuntar algunas de ellas. El asentamiento del neoliberalismo, con el correspondiente socavamiento de la sociedad del bienestar, fomenta el individualismo y el desentendimiento de las responsabilidades colectivas. No es de extrañar que ello origine simultáneamente despreocupación por el aseguramiento de espacios no segregados de interacción social, y por los espacios públicos en general. Con frecuencia ese desinterés lleva a la privatización de los espacios públicos en cuanto se les puede sacar un rendimiento. Por otro lado, se han acentuado las tendencias de segregación social 
residencial, de las que son solo un ejemplo el aburguesamiento de barrios y las urbanizaciones cerradas. A esta transformación no ha escapado el diferenciado modo de vida mediterráneo, dados la pérdida de prestigio de la tradicional ciudad compacta a favor de la diseminada y la tendencia a localizar las viviendas sociales fuera de la trama urbana consolidada. Los barrios pobres, que no pueden disponer por sí mismos de los recursos necesarios para mejorar su habitabilidad ni tienen la influencia política necesaria, sufren un proceso de degradación de las condiciones de vida. Finalmente, la competencia entre las ciudades para atraer inversiones turísticas, comerciales, financieras o de otro tipo requiere que ciertos espacios ciudadanos, singularmente los centros urbanos, sean objeto de una transformación teatral, que exige ocultar o enmascarar algunos lugares y desterrar a determinados colectivos de esos espacios (Baumann, 2006; Cerezo Domínguez y Díez Ripollés, 2011; Medina, 2011; Young, 2003).

\section{Su repercusión sobre colectivos penalmente sospechosos.}

Esa reorganización de las ciudades incide de manera significativa sobre ciertos grupos proclives a entrar en conflicto con la ley penal, en los que esa transformación urbana dificulta apreciablemente su ya deficiente inclusión social. Así, se priva a los sin techo y marginados sociales de lugares imprescindibles para satisfacer sus necesidades vitales básicas o de convivencia, o se desposee a los jóvenes de espacios de socialización favorecedores de su maduración personal. En realidad los efectos negativos se hacen sentir sobre la ciudadanía en general: Se extiende un manto de sospecha y desconfianza sobre el comportamiento que cualquier ciudadano pueda realizar en lugares públicos o lugares privados de acceso público.

Pero detengámonos en los colectivos primeramente aludidos y valoremos la medida en que esas modificaciones urbanas modifican el control social habitualmente ejercido sobre esos grupos, sospechosos en cuanto no normalizados. Ante todo, cabe destacar que los grupos antedichos padecen en los últimos tiempos una estigmatización acentuada que repercute en un incremento de su control en los espacios públicos que usan. Se ha asumido, por lo general acríticamente, que esos modos de vida marginales o esas conductas incívicas, en ocasiones productores de conductas delictivas de limitada 
importancia, son reflejo o antesala de conductas delictivas más graves; o simplemente se ha reducido el umbral de lo aceptable en espacios públicos o en espacios privados de acceso público.

Ese mayor control no se orienta por la conducta delictiva realizada o prevenida, sino por el estatus social atribuido a determinadas personas, estatus que se establece discrecionalmente a partir de su apariencia o forma de vida. Objetivo primordial de ese control, por otra parte, es desplazar a esos ciudadanos de ciertos espacios urbanos, y no tanto castigar, mucho menos resocializar; supone el triunfo de la teoría de las ventanas rotas frente al enfoque algo más empático de la policía comunitaria. Por lo demás, las técnicas que sirven a ese control de los lugares públicos o privados de acceso público no suelen ser objeto de cuestionamiento en sus fundamentos, limitándose la oposición a buscar compromisos que respeten ciertos derechos de los afectados (Baumann 2007; Beckett y Herbert 2008; Beckett y Herbert, 2010; Cerezo Domínguez y Díez Ripollés, 2011; Coleman y Sim, 2005; Doherty, Busch-Geertsema, Karpuskiene et al. 2008; Herbert, 2001; Mork Lomell, 2004; Young, 2003).

A continuación voy a analizar tres fenómenos relativos al control de los espacios públicos. Pero antes conviene señalar que este estudio se integra en una iniciativa investigadora más amplia con la que se pretende validar un instrumento de comparación de los sistemas político-criminales nacionales del mundo desarrollado. Ese instrumento adopta como punto de referencia la dimensión inclusión / exclusión social, en lugar de otros criterios más usuales. Esa dimensión no pretende medir los efectos sociales incluyentes o excluyentes que un determinado sistema de control penal nacional produce en el conjunto de la población, sino que concentra su atención en las personas o colectivos que son objetivo prioritario de los órganos de prevención y persecución penales, fundamentalmente sospechosos, delincuentes y exdelincuentes.

Para materializar el citado instrumento comparativo he propuesto un conjunto de indicadores agrupados en 9 cestas, estando cada una de ellas centrada en un tema relevante de la política criminal contemporánea. Se trata de desarrollar una escala que mida la dimensión inclusión / exclusión social en los diferentes sistemas de control penal nacionales a partir de los resultados obtenidos en esos indicadores, y que permita localizar a cada país estudiado en un determinado lugar de un continuo cuyos dos extremos estarían constituidos por los dos sistemas nacionales más contrapuestos. 
Además, he afirmado que hay suficientes indicios para anticipar que una mayoría de los estados de Estados Unidos de América y su sistema federal podrían estar en el extremo de la exclusión social, mientras que los países nórdicos europeos -Dinamarca, Finlandia, Noruega y Suecia- podrían encontrarse en el otro extremo de la inclusión social (Díez Ripollés, 2011).

Mientras los esfuerzos para concretar y validar ese instrumento de medida siguen su curso bajo el impulso de un equipo de investigadores del Instituto de Criminología de la Universidad de Málaga, puede resultar interesante profundizar en la capacidad de los indicadores propuestos para reflejar efectos incluyentes o excluyentes, así como comprobar si se registran los contrastes predichos en reglas y prácticas entre los Estados Unidos y los países nórdicos europeos.

Para ello voy a centrarme en una de las cestas de indicadores, aquella que se ocupa justamente de las diversas reglas y prácticas que se están consolidando en nuestras sociedades para el control de los sospechosos en los espacios públicos. Así, voy a analizar las urbanizaciones cerradas y el aburguesamiento de determinados barrios, el uso de videocámaras en lugares públicos y privados de acceso público, y las nuevas técnicas de prohibición de acceso a determinados espacios ciudadanos. Y voy también a verificar las diferencias que se aprecian al respecto entre los dos grupos de países aludidos.

\section{Las urbanizaciones cerradas y el aburguesamiento de barrios.}

Las urbanizaciones cerradas son desarrollos inmobiliarios constituidos por una pluralidad de edificios residenciales que interponen obstáculos físicos de acceso a lo largo del perímetro de la urbanización. Esos obstáculos se acompañan de controles en las vías de acceso a la urbanización de naturaleza personal y/o electrónica. Por lo general se procura que el mayor número posible de servicios generales se presten dentro de la propia urbanización -comercios, escuelas, centros de salud, instalaciones deportivas o de recreo...-, con la pretensión de reducir la necesidad de interactuar con el exterior de la urbanización.

El fenómeno de las urbanizaciones cerradas -gated communities- está muy generalizado en las ciudades estadounidenses, con datos elocuentes al respecto. A 
comienzos de siglo, alrededor de 9 millones de estadounidenses viven en ellas, se calcula que hay tres millones de unidades residenciales integradas en ellas, y en muchas áreas urbanas constituyen una mayoría de las promociones en marcha (Lynch, 2001; Midtveit, 2005).

En una primera aproximación puede entenderse que, al reforzar la seguridad personal de sus residentes frente a conductas delictivas o incívicas, son un medio de promoción de las relaciones personales entre los habitantes de la urbanización. Sin negar que tal cosa suceda, lo cierto es que constituyen un relevante mecanismo de renuncia a la interacción social con el conjunto de los ciudadanos. Los no residentes pasan por ese mismo hecho a ser sospechosos, y precisan de un aval interno para acceder al privilegiado entorno en el que tienen lugar relaciones personales selectivas. Los desconocidos y los extraños en general no pueden participar en ellas. En último término, estamos ante un instrumento de homogeneización social, y con frecuencia racial, que posibilita la segregación voluntaria de grupos de población con niveles socioeconómicos medios y altos de los restantes colectivos integrantes de la sociedad.

Estos últimos, si no comparten las características socioeconómicas precedentes, tienen fuera de su alcance esas zonas residenciales: Su deseo de residir en ellas se ve frustrado por su incapacidad para cumplir los requisitos de precio o extracción social o racial artificialmente predeterminados por promotores inmobiliarios o residentes. No sin razón se ha afirmado que tales urbanizaciones suelen contravenir en su modo de operar la prohibición de discriminación en el mercado de la vivienda. Del mismo modo, todo intento de acceder a ellas al margen de los controles establecidos convierte a quienes lo intentan en sospechosos de infringir la ley penal, o directamente en infractores. De una manera u otra, estamos ante una tecnología privatizadora de espacios y servicios públicos que dificulta al conjunto de ciudadanos, con su asentimiento o sin él, interactuar entre sí, lo que genera exclusión social en unos e incomprensión social en otros (Baumann, 2006; Lynch, 2001; Medina, 2011; Midtveit, 2005).

Se ha teorizado que se trata de un fenómeno paralelo al del encarcelamiento masivo de nuestros días: Si un porcentaje significativo del colectivo pobre de nuestra sociedad se encuentra en prisión, encerrado involuntariamente, una parte cada vez mayor de los sectores acomodados de la sociedad se encierra voluntariamente en sus urbanizaciones y renuncia con gusto a establecer relaciones sociales con quienes no 
pertenecen a su estrato social. Si a eso se une el fenómeno del progresivo cerramiento de los complejos de viviendas sociales, que veremos más adelante, se aprecian rasgos inquietantes de desaparición del concepto de sociedad como comunidad de convivencia, a favor de una mera yuxtaposición de colectivos con escasa interrelación entre ellos y con el consecuente desentendimiento de los compromisos y obligaciones comunes (Lynch, 2001; Simon, 2007).

No es frecuente encontrar urbanizaciones cerradas en los países nórdicos europeos, donde tienen una presencia muy limitada (Lappi-Seppälä, 2014; Midtveit, 2005).

Lo más parecido a ello en estos países es el fenómeno de aburguesamiento de determinados barrios céntricos o bien situados de las ciudades. Como es sabido, políticas de recuperación de zonas urbanas degradadas, en especial cuando ofrecen claros incentivos de lucro a promociones inmobiliarias privadas, dan lugar a una rehabilitación de esas áreas que con frecuencia modifica notablemente la población residente. La mejora de viviendas y equipamientos, cuando no su casi general sustitución, hace subir sustancialmente los precios de la vivienda que pasan a ser accesibles solo a personas de clase media o media-alta, en contraste con los precedentes residentes de niveles sociales más bajos. La consecuente modificación, renovación y, en todo caso, encarecimiento de los comercios del barrio, los cuales se acomodan a las demandas de los nuevos residentes, así como las plusvalías generadas por la venta de viviendas pendientes de rehabilitación hacen que se produzca la práctica desaparición de los residentes originales.

En la medida en que no se establezcan planes encaminados a preservar la residencia en ese mismo barrio de la población anterior en viviendas restauradas, estamos sin duda ante una técnica de exclusión social de naturaleza espacial. En realidad, la tolerancia del aburguesamiento de barrios ciudadanos refleja una tendencia política de mayor alcance: supresión de los esfuerzos por garantizar una composición interclasista de los diferentes barrios urbanos, objetivo que en otro tiempo fue impulsado mediante la localización de los complejos de viviendas sociales en muy diferentes sectores de la trama urbana y no en su extrarradio devaluado (Lappi-Seppälä, 2014; Medina, 2011; Midtveit, 2005). Otra manifestación de tolerancia hacia ese aburguesamiento es la renuncia a contrarrestar las resistencias vecinales a la construcción de edificios municipales destinados a prestar servicios asistenciales a 
colectivos desfavorecidos; pese a su buena localización dentro de la trama ciudadana, termina siendo inimaginable su radicación en tales barrios (Lappi-Seppälä, 2014).

Conseguida esa segregación social, su mantenimiento, impidiendo que marginados y pobres estén presentes en barrios recuperados para las clases acomodadas, no se produce mayoritariamente mediante obstáculos físicos o electrónicos, a juzgar por diversas experiencias nórdicas. Se utilizan técnicas simbólicas más suaves, como las de saturación: El fuerte incremento de la presencia de personas de niveles socioeconómicos medios y altos en esos lugares, sean residentes sean personas que se sirven de la nueva oferta comercial o de ocio de esos barrios, hace que la presencia de colectivos de niveles bajos o marginales se convierta en primer lugar en llamativa para todos y más adelante en incómoda para estos últimos grupos. Sometidos a un fuerte control social informal, terminan abandonando esas zonas urbanas (Borch, 2005; Midtveit, 2005).

\section{El uso de videocámaras en lugares públicos o privados de acceso público.}

El uso de videocámaras en lugares públicos o lugares privados de acceso público persigue normalizar, más bien restringir, los comportamientos que pueden realizarse en determinadas zonas urbanas, singularmente centros históricos y comerciales. Se ha podido constatar que la frecuencia del uso de videocámaras es tanto mayor cuanto más arraigado se encuentre en la sociedad el pensamiento neoliberal, menor aprecio se dé en ella a la privacidad, menor atención se preste a la evaluación de la eficacia de las políticas públicas, y mayor promoción de su implantación se haga por parte de los poderes públicos. Su empleo masivo parte de un concepto de prevención descontextualizado, de carácter situacional, que autonomiza lugares concretos como fuente de delitos o conductas incívicas, sin tener debidamente en cuenta los factores sociales generadores de criminalidad o desórdenes en la ciudad (Anderson, 2012; Björklund, 2013; Coleman y Sim, 2005; Murakami Wood, 2009; Norris y McCahill, 2006; Norris, McCahill, y Wood, 2004; Welsh y Farrington, 2009).

Sin embargo, su objetivo primordial de prevenir la delincuencia se ha mostrado en gran medida vano. Abundantes estudios empíricos sobre lugares públicos han demostrado que efectos reductores de la delincuencia solo se aprecian en lugares muy delimitados, restringidos a los delitos contra la propiedad, y con frecuentes efectos de 
desplazamiento o difusión. En realidad, se ha probado que existen medidas más eficaces para prevenir la delincuencia en los lugares públicos, y menos contraproducentes, como un adecuado alumbrado o la reducción de la permeabilidad vial de ciertas zonas (Cerezo Domínguez y Díez Ripollés, 2011; Hempel y Töpfer, 2009; Huey, 2010; Medina, 2011; Welsh y Farrington, 2009) ${ }^{2}$.

Por otra parte, debemos ser conscientes de que una aproximación valorativa a esta técnica de control no debe limitarse al respeto que merecen la intimidad o privacidad de los ciudadanos en lugares públicos o privados de acceso público. Sin negar su relevancia, es indudable que existe una cierta tolerancia social a afecciones a la intimidad en lugares públicos y asimilados producidas por grabaciones de videocámaras, por más que se discrimina según lugares, intensidad y condiciones. En este último sentido, hay fuerte resistencia al uso de dispositivos de audio, se otorga especial importancia a la identificación y limitación de las personas con acceso autorizado a esas imágenes, y se exige el borrado de ellas transcurrido un tiempo.

Sin embargo, existe otro enfoque valorativo, presente en algunas jurisdicciones como la española o la alemana, que pone el énfasis en el derecho fundamental a la protección de datos personales, el cual expresa en este ámbito la legítima pretensión del ciudadano de controlar la información que se obtiene de él en lugares públicos o privados de acceso público. No se trata de que se respete su privacidad, necesariamente limitada en esos lugares, sino de que el ciudadano pueda determinar aquellos aspectos de su personalidad con los que quiere ejercer sus derechos individuales, sociales y políticos en una sociedad democrática. La captación o difusión indiscriminada de sus datos personales, no necesariamente privados, imposibilita tal cosa. Así, el uso de videocámaras en lugares públicos y asimilados obliga al ciudadano a modificar comportamientos espontáneos, no dañosos socialmente, para preservar su imagen social, o a evitar determinados lugares por la misma razón (Björklund, 2013; Cerezo Domínguez y Díez Ripollés 2011; Gras, 2004; Hempel y Töpfer, 2009; Rudinow Soetnan, Mork Lomell y Wiecek, 2004; Welsh y Farrington, 2009).

Pero lo relevante para nuestro propósito es el papel de las videocámaras urbanas como instrumento de exclusión social. Se han convertido en un formidable recurso para

\footnotetext{
2. Sobre la escasa efectividad de las salas de control, Norris y McCahill (2006). Sobre la no acreditada eficacia de las videocámaras instaladas en taxis, Anderson (2012).
} 
alejar a determinados colectivos o tipos de personas de ciertos espacios urbanos. Ese papel lo adquirieron tempranamente en los espacios privados de acceso público, pero se ha terminado extendiendo también a las calles, plazas y otros lugares públicos. La facilidad que estos aparatos ofrecen para localizar e identificar a aquellos ciudadanos a los que se quiere proscribir el acceso o estancia en esos lugares se aprovecha para conseguir los efectos de selección de clientela, segregación social residencial y transformación teatral de los centros urbanos, entre otras metas, que ya hemos mencionado. No es casual a este respecto que fueran las ciudades turísticas las primeras que, para preservar su ilusoria imagen, generalizaran el uso de cámaras en lugares públicos.

Las personas sobre las que centran su atención esas videocámaras manejadas con ese fin ya nos son conocidas. Se trata de los colectivos sospechosos clásicos, marginados sin actividad laboral conocida, ciudadanos que viven en la calle, pobres sin capacidad de consumo, pandillas de jóvenes con ganas de divertirse, personas que desentonan con el ambiente que les rodea, etc. En suma, ciudadanos identificados mucho más por su apariencia que por las conductas concretas que realizan. De hecho, su exclusión social no se produce tanto por la vigilancia a que son sometidos como por las intervenciones subsiguientes sobre el vigilado indeseable y su frecuencia (Björklund, 2013; Coleman y Sim, 2005; Hempel y Töpfer, 2009; Mork Lomell, 2004; Norris y McCahill, 2006; Norris, McCahill y Wood, 2004; Rudinow Soetnan, Mork Lomell y Wiecek, 2004; Welsh y Farrington, 2009). ${ }^{3}$

En la mayoría de los países nórdicos europeos las videocámaras en lugares públicos tienen una presencia muy limitada, siendo más frecuente su instalación en lugares privados de acceso público (Gras, 2004; Mork Lomell, 2004; Norris, McCahill y Wood, 2004; Rudinow Soetnan, Mork Lomell y Wiecek, 2004).

Entre las causas de su reducido arraigo se citan, en línea con lo antes apuntado, la asentada ideología bienestarista de esas sociedades, su tradición de evaluación de los efectos de las políticas públicas lo que cierra con frecuencia el paso a políticas meramente simbólicas, y los obstáculos legales a su implantación en lugares públicos o

\footnotetext{
${ }^{3}$ De ahí que no sorprenda que ciertos personas especialmente marginadas, que desenvuelven su vida habitualmente en lugares muy frágiles, sin desconocer la verdadera función de la vigilancia electrónica a veces manifiestan sentirse más seguras al saber que ellas mismas, pero también todos los que les rodean, están vigilados; se trata de lugares asistenciales especialmente destinados a ellos $\mathrm{y}$, en mucha menor medida, de lugares públicos en general (Huey, 2010).
} 
asimilados, en especial si son operadas por agentes privados. No faltan, sin embargo, advertencias sobre el incremento de su uso (v. Hofer, 2000; Loftsson, 2013; Norris, McCahill y Wood 2004).

En cualquier caso, como en el resto de la Unión europea ${ }^{4}$, rige plenamente en ellos la Directiva europea 95/46 de protección de datos personales, que contiene un elaborado sistema de protección de esos datos, el cual afecta directamente a la obtención de imágenes y audiciones en lugares públicos y asimilados ${ }^{5}$. Las correspondientes leyes nacionales nórdicas de implementación de la Directiva adoptan en su mayoría una actitud cautelosa respecto al uso de videocámaras en tales lugares (Björklund, 2013; Gras, 2004; Lohne, 2012; Norris, McCahill y Wood, 2004; Rudinow Soetnan, Mork Lomell y Wiecek, 2004; Welsh, y Farrington, 2009). Entre otros motivos, en ello ha influido el hecho de que, antes de que entrara en vigor la directiva y obligara a la creación de agencias nacionales de protección de datos, ya existían en algunos de estos países esos organismos con el objetivo específico de proteger la privacidad y los datos personales de los ciudadanos. A tal fin tenían competencias de registro de los dispositivos instalados y facultad sancionadora de las infracciones a la regulación vigente. De hecho, estas agencias constituyen en ocasiones un importante referente en el debate público sobre estas materias, en el que participan ${ }^{6}$.

En Suecia rige un sistema de autorización previa por parte de autoridades administrativas supralocales, a partir de solicitudes debidamente motivadas, con objetivos limitados y que se someten a informe de la autoridad municipal ${ }^{7}$. Bancos, oficinas de correos y determinados espacios de las tiendas deben únicamente notificar la instalación a la autoridad administrativa, siempre que se limiten a usar cámaras fijas con fines exclusivos de prevención y detección del delito. Es obligatorio informar al público de su presencia, solo los encargados de la vigilancia pueden acceder a las grabaciones, $\mathrm{y}$

\footnotetext{
${ }^{4}$ A la que pertenecen Dinamarca, Finlandia y Suecia, mientras que Noruega incorpora con asiduidad a su legislación los contenidos de la legislación europea.

${ }^{5}$ Véase Directiva 95/46/CE, del parlamento y del consejo de la Unión Europea, de 24 de octubre de 1995. De relevancia es igualmente el Dictamen 4/2004, de 11 de febrero de 2004, sobre Procesamiento de datos personales mediante videovigilancia, adoptado por un Grupo de trabajo de la UE constituido al efecto. Un análisis jurídico específico en Cerezo Domínguez y Díez Ripollés, 2011.

${ }^{6}$ Véase un ilustrativo análisis de la agencia de protección de datos noruega en Lohne 2012. No es el caso, sin embargo, de la agencia de protección de datos sueca, la cual ya no tiene competencias sobre la instalación de videocámaras en lugares públicos o privados de acceso público (Björklund, 2013; Loftsson, 2013).

${ }^{7}$ Con todo, algún autor llama la atención sobre la posibilidad de operar sin autorización durante un mes, o mientras se sustancia esa autorización y eventualmente el recurso tras su denegación (Loftsson, 2013).
} 
estas deben borrarse transcurrido un mes salvo excepciones derivadas de la persecución de delitos o de algunas infracciones administrativas. La policía está sometida a las mismas condiciones legales para instalar y operar videocámaras en lugares públicos, por más que se admiten excepciones para determinados propósitos (Björklund, 2013; Gras, 2004; Loftsson, 2013; Tham, 2001).

Las cifras de instalación de videocámaras en lugares públicos o privados de acceso público siguen siendo bajas en Suecia, a pesar de que se están incrementando notablemente en los últimos años ${ }^{8}$. Así, el número de cámaras que solicitaron autorización para ser instaladas o cuya instalación fue notificada, sobre todo en lugares privados de acceso público -con especial frecuencia en líneas de transporte público-, ha pasado de 5.000 en 1996 a 18.000 en 2008. Las autoridades administrativas conceden la mayor parte de las solicitudes, lo que ha llevado a que los permisos hayan aumentado un 45\% entre 2005 y 2008. A su vez, las funciones de control por la autoridad administrativa del correcto uso de las videocámaras instaladas parece que por motivos de carga de trabajo han sido en gran medida descuidadas (Björklund, 2013; Gras, 2004; Loftsson, 2013).

De todos modos, aun dentro de la parsimoniosa regulación y utilización de las videocámaras en Suecia, el debate sobre su expansión se desenvuelve en un plano fundamentalmente utilitario, el de su capacidad para prevenir las conductas delictivas en el marco de la prevención situacional. Está soportado por una opinión pública básicamente favorable, escasamente consciente de los serios cuestionamientos empíricos a su eficacia para prevenir delitos, y con una administración municipal cada vez más implicada en la implantación de tales dispositivos. Un factor proclive a la ausencia de un debate político e ideológico es que la privacidad no ha adquirido rango de derecho fundamental en Suecia sino que es un interés más a ponderar con el de seguridad o el de prevención de delitos; en ese contexto se aprecia una clara pérdida de peso del primero frente a los segundos (Björklund, 2013; Loftsson, 2013).

En Noruega no hay tradición de su instalación en lugares públicos ni en comercios ordinarios, pero se está incrementando su uso en lugares privados de acceso público como centros comerciales y nudos de transporte. En esos lugares privados de acceso público que disponen de ellas la práctica es intervencionista, pues da lugar a frecuentes

\footnotetext{
${ }^{8}$ Una comparación entre Suecia y Reino Unido, con datos de 2000, en Gras (2004).
} 
expulsiones de personas de esos espacios (Mork Lomell, 2004; Rudinow Soetnan, Mork Lomell y Wiecek 2004). A fecha de 2004 solo ha habido alguna experiencia aislada en una plaza pública céntrica, la cual tuvo lugar en 1999: A demanda de un grupo de comerciantes que quería sanear el lugar, se quiso intervenir sobre el menudeo de droga que en él acaecía, aunque la policía tenía la intención preferente de disuadir a consumidores jóvenes primarios de acudir allí; con todo, el empleo de las cámaras no fue sistemático ni masivo como tampoco las intervenciones sobre los identificados, consistentes en prohibirles el acceso al lugar. Al poco tiempo se abandonó la experiencia. Las razones fueron, por un lado, el reconocimiento del derecho de esas personas a estar en ese lugar y, por otro, los efectos de desplazamiento difuso y consecuente empeoramiento de las capacidades de control del fenómeno que se estaban produciendo (Mork Lomell, 2004; Rudinow Soetnan, Mork Lomell y Wiecek, 2004).

En Dinamarca la regulación existente prohíbe su instalación en lugares públicos o privados de acceso público, salvo excepciones debidamente autorizadas, y su instalación debe siempre advertirse. Sin embargo, hay escasas limitaciones para su uso policial, incluso de modo encubierto (Gras, 2004; Norris, McCahill y Wood, 2004).

En Finlandia, sin embargo, la situación es muy distinta a la de los países precedentes. Diversas estimaciones apuntan a que, tras el Reino Unido, es el país de Europa occidental con más videocámaras instaladas en proporción a la población. Ciertamente su ley de protección de datos se encarga de prohibir la captación de imágenes en espacios privados, y de restringir el uso de cualesquiera imágenes registradas en cualquier espacio, público o privado, en la medida que pasan a constituir un registro de datos personales. Pero se carece de una regulación específica sobre instalación de videocámaras en lugares privados de acceso público, incluso en lugares públicos, existiendo únicamente unas directrices policiales. En consecuencia, no existe un sistema de autorización previa de su instalación en cualquiera de esos lugares, y no siempre es preciso advertir de su existencia (Lappi-Seppälä, 2014).

En los Estados Unidos parece estar muy extendida la instalación de videocámaras en lugares privados en condiciones de captar sin restricciones legales lo que sucede en lugares públicos, manipuladas por personas privadas o públicas. Además, su uso en lugares privados de acceso público es extremadamente frecuente. Había, sin embargo, un cierto retraso en su instalación en lugares públicos, el cual se está superando 
rápidamente tras los atentados del 11 de septiembre de 2001 (Anderson, 2012; Norris, McCahill y Wood, 2004; Welsh y Farrington, 2009). Con todo, ya en 1996 el 75\% de las instalaciones mercantiles utilizaban videocámaras, y en esas fechas su volumen de ventas ya había superado al de los sistemas de alarma antiincendios o antirrobo; del mismo modo, solo en 2002 se estima que se vendieron dos millones de videocámaras (Norris, McCahill y Wood, 2004).

Pero lo verdaderamente significativo de la situación estadounidense es la generalizada ausencia de un marco normativo, federal o estatal, que regule el uso de estos aparatos de forma que, cuando menos, se pueda atender a los intereses implicados de privacidad, intimidad o protección de datos personales de los ciudadanos. Por lo demás, algunos círculos jurídicos han cuestionado el empleo excesivo de videocámaras en lugares públicos o lugares privados de acceso público desde una perspectiva constitucional, pero no se han producido avances reales en esa línea (Murakami Wood, 2009; Norris, McCahill y Wood, 2004; Welsh y Farrington, 2009). Ocasionalmente en algún estado, como California, se ha impulsado alguna iniciativa legal, que no ha llegado aún a tener éxito, la cual, en aras del respeto de la privacidad, ha querido asegurar que su uso en lugares públicos y asimilados se restrinja a la prevención y persecución de delitos. A ese propósito, cuestiones como el rechazo de dispositivos de audio, el exclusivo acceso a las imágenes por la policía, o su borrado transcurrido cierto tiempo comienzan a ser debatidas (Anderson, 2012). En suma, se podrá cuestionar el uso excesivo de videocámaras en lugares públicos o asimilados, pero, en general, no hay especial preocupación por la legitimidad de su uso en cualesquiera circunstancias y condiciones, y la inquietud generada por los atentados del 11 de septiembre de 2001 no favorece un cambio de actitud (Anderson, 2012; Welsh y Farrington, 2009).

Un buen ejemplo de su aceptación social es su empleo irrestricto en taxis. Las videocámaras se instalaron inicialmente con el objetivo de prevenir delitos de clientes y taxistas, siendo la policía la única autorizada a acceder a las imágenes obtenidas. Paulatinamente se han convertido en un medio de acreditar la culpabilidad en los accidentes, con las compañías de seguros promoviendo activamente su instalación, así como de controlar el desempeño laboral del taxista por parte de los dueños de la empresa. Tales intereses han hecho que las cámaras hayan pasado a enfocar la calle, que 
lleven dispositivos de audio, y que no haya limitaciones de acceso a las imágenes obtenidas ni obligaciones de borrado (Anderson, 2012).

\section{Técnicas de prohibición de acceso a determinados espacios ciudadanos.}

Por técnicas de prohibición de acceso de ciertas personas o grupos a lugares públicos o lugares privados de acceso público entiendo la interdicción de entrada o estancia en parques públicos, las prohibiciones de estancia en zonas de menudeo de drogas o de prostitución, las prohibiciones de entrada a zonas comerciales u otros lugares privados de acceso público, y la inadmisión en complejos residenciales privados (Beckett y Herbert, 2008; Beckett y Herbert, 2010; Coleman y Sim, 2005). Otras técnicas semejantes, como los toques de queda juveniles o la prohibición de entrada o estancia en ciertos lugares de pandillas juveniles van a quedar fuera de nuestra consideración (Beckett y Herbert, 2010; Coleman y Sim, 2005).

Estamos ante técnicas de control social en gran parte novedosas, y de naturaleza singular. Para manejar la pretendida peligrosidad social o criminal de ciertos grupos o individuos no se adoptan medidas directamente encaminadas a perseguir o prevenir los comportamientos antisociales o delictivos que han realizado o que se teme que van a realizar. Lo que se hace es cerrar espacios ciudadanos de interacción social a colectivos o personas en función de su apariencia o forma de vida, sin necesidad alguna de argumentar que hay motivos para pensar que han realizado o van a realizar esas temidas conductas. En cuanto mecanismo de desplazamiento delictivamente inmotivado de ciudadanos fuera de ciertos espacios urbanos públicos o asimilados se alejan de las modernas penas o medidas restrictivas de la libertad de movimientos para prevenir la reiteración en el delito, y se asemejan más a la antigua pena de extrañamiento (Beckett y Herbert, 2010; Coleman y Sim, 2005).

No resulta difícil colegir que son técnicas específicamente diseñadas para concentrar su incidencia sobre ciudadanos con problemas de inclusión social, que han quedado al margen de la sociedad de consumo actual o que todavía no han accedido a ella. Estamos ante un colectivo cada vez más numeroso y omnipresente en algunos países, consecuencia del incremento de las desigualdades sociales y de la reducción o anulación de las políticas sociales de vivienda, salud, educación o asistencia, entre otras. 
Se trata de que los mayoritarios sectores sociales que han accedido en mayor o menor medida a esos niveles de consumo no se vean perturbados en su actividad cotidiana por la visión de unos modos de vida que se perciben como molestos. En último término, aparecen de nuevo los intereses financieros, comerciales y de estatus social ligados a la teatralización de los centros de las ciudades y el aburguesamiento de determinados barrios, entre otros fenómenos ya mencionados (Beckett y Herbert, 2010; Coleman y Sim, 2005).

El desenvolvimiento de estas técnicas en numerosas ciudades de Estados Unidos está bien acreditado, así como su proliferación (Beckett y Herbert, 2010). En realidad constituyen un perfeccionamiento de técnicas anteriores, las cuales tropezaban con obstáculos judiciales u operativos. Las tradicionales leyes de vagos hubieron de desaparecer dadas las objeciones judiciales a su indeterminación y falta de respeto al derecho penal del hecho. Las ordenanzas cívicas que las sustituyeron, al centrarse sobre acciones concretas realizadas, no disponían de la discrecionalidad policial buscada. El precedente inmediato de estas técnicas han sido las órdenes de alejamiento vinculadas a la simple alegación policial de una manifiesta intención de cometer un delito (Beckett y Herbert, 2008; Beckett y Herbert, 2010).

Las ordenanzas de exclusión de parques permiten a policías y encargados de esos espacios a sacar del parque a quienes infrinjan sus reglas de estancia, normalmente ligadas a meras pautas de urbanidad y civismo. Ello suele conllevar la prohibición de acceso a algunos o todos los parques de la ciudad durante un significativo periodo de tiempo. La infracción de esa prohibición de acceso, de naturaleza administrativa, constituye una infracción penal que puede dar lugar a privaciones de libertad durante meses (Beckett y Herbert, 2008; Beckett y Herbert, 2010).

Las órdenes de alejamiento de sectores urbanos con menudeo de drogas u oferta de prostitución, impuestas en el marco de las condiciones de suspensión de la pena o del sistema de prueba o incluso como medida cautelar, se han desnaturalizado hasta el punto de que terminan abarcando sectores muy extensos de las ciudades, entre los que se cuenta todo el centro urbano. Con frecuencia imposibilitan un desplazamiento normal de los afectados por el conjunto de la ciudad. Su infracción origina consecuencias penales privativas de libertad (Beckett y Herbert, 2008; Beckett y Herbert, 2010). 
Las prohibiciones de entrada en lugares privados de acceso público ya no se limitan a impedir el acceso a las instalaciones correspondientes, sino que abarcan las aceras adyacentes de uso público y, cada vez más, el espacio público que rodea el lugar donde esas instalaciones está localizadas. Es el caso de áreas o barrios comerciales, centros históricos, campus universitarios, complejos hospitalarios o nudos de transporte, entre otros. Para ello se delega en la policía el derecho del propietario de no admitir a ciertas personas en sus instalaciones, y aquella procede a una interpretación extensiva de la prohibición a los espacios públicos circundantes. Con frecuencia, la prohibición de acceso a cierta instalación se extiende a todas aquellas de la misma naturaleza. Esas prohibiciones de entrada, de naturaleza administrativa, no precisan ser motivadas y suelen extenderse durante meses. Su infracción constituye un ilícito penal castigado con prisión (Beckett y Herbert, 2008; Beckett y Herbert, 2010).

Las prohibiciones de acceso a viviendas sociales o urbanizaciones de vivienda pública muestran una tendencia expansiva semejante. Los administradores de esos complejos residenciales, con el argumento parcialmente fundado de la prevención de delitos, con frecuencia impiden el acceso a ellos e incluso a sus zonas aledañas a todo aquel que no sea residente, incluidas visitas de familiares, amigos o personas con algún interés legítimo. Aunque los jueces suelen admitir los recursos de los inquilinos, pero no de los visitantes, contra prohibiciones indiscriminadas, no cuestionan que se prohíba el acceso a quienes tienen o han tenido antecedentes delictivos mientras subsista una peligrosidad que no tiene por qué establecerse judicialmente ${ }^{9}$. Frente a las infracciones de esas advertencias de prohibición de acceso emitidas por los administradores reacciona la policía entrando en las viviendas y deteniendo a quienes se encuentran indebidamente dentro por comisión de un ilícito penal. En realidad estas prácticas han terminado por caer dentro de las desdeñables prácticas de discriminación policial (Díez Ripollés, 2014; Goldstein, 2003).

Para facilitar el desarrollo de estos medios de control espacial se ha dotado a estas técnicas de un carácter jurídico mixto, administrativo-penal. De esta forma, sirviéndose del derecho administrativo en las primeras intervenciones sobre esas personas, se posibilita actuar sobre conductas que no son delictivas, se incrementa la discreción

\footnotetext{
${ }^{9}$ Sobre los riesgos de desahucio que corren los inquilinos que admiten a ciertas personas en esas viviendas sociales, aunque sean familiares (Díez Ripollés, 2014).
} 
policial, se eluden exigencias garantistas penales y se facilita la tarea de la fiscalía en la prevención de delitos. Todo ello en un contexto de expansión del control social formal. Esa combinación de perspectivas se extiende en ocasiones a la administración penitenciaria, mediante la creación de patrullas mixtas de policías y funcionarios de prueba, que se encargan de controlar simultáneamente las infracciones a las prohibiciones de acceso tanto de advertidos administrativamente como de sometidos a suspensión de la pena o a libertad condicional (Beckett y Herbert, 2008; Beckett y Herbert, 2010).

En los países nórdicos han surgido igualmente prácticas de exclusión de determinadas personas de lugares públicos o lugares privados de acceso público, pero su desarrollo ha sido contenido y, al ser cuestionadas, no han podido consolidarse. Suelen venir ligadas a la penetración paulatina del modelo de seguridad ciudadana, con su énfasis en la gestión de riesgos y la prevención situacional, y la ampliación de los objetivos sometidos a control. Sin negar sus avances, lo cierto es que todas esas nuevas técnicas de control ciudadano terminan en buena parte, aunque no siempre, integradas en la tradición nórdica de prevención del delito a través de intervenciones bienestaristas sobre grupos socialmente vulnerables y la implicación de la sociedad civil (Björklund, 2013; Borch, 2005; Jepsen, 1996; Midtveit, 2005; Torrönen, 2004; Torrönen y Korander, 2005; Virta, 2013) ${ }^{10}$.

Diversas experiencias en Finlandia han querido actuar sobre colectivos perturbadores de espacios públicos urbanos, singularmente grupos de jóvenes desordenados, pero también borrachos o consumidores de droga. Su análisis muestra las resistencias con que tropiezan los programas centrados en técnicas de exclusión espacial entre los agentes sociales y políticos y en la propia sociedad. Sin perjuicio de que alguna ciudad ha sacado adelante un plan moderado de tal naturaleza, predominan intervenciones bienestaristas, de prevención de la exclusión social, frente a las de naturaleza securitaria y policial (Torrönen, 2004; Torrönen y Korander, 2005; Virta, 2013).

\footnotetext{
${ }^{10}$ Borch (2005) hace un análisis sugerente desde Dinamarca de los riesgos de la expansión de técnicas preventivas espaciales, no siempre excluyentes, desde la perspectiva del modelo bienestarista; Virta (2013) examina la ampliación de los objetivos de control en los sucesivos programas de seguridad fineses, y la consolidación de técnicas de gestión de riesgos.
} 
En Dinamarca, varios planes de sacar de determinados espacios públicos actividades de menudeo de droga, prostitución y economía informal mediante intervenciones policiales se han considerado fracasados: En uno de ellos los efectos de desplazamiento e incluso de retorno, a pesar de las prohibiciones de acceso y detenciones subsiguientes, llevaron a abandonar el programa. En otro, los enérgicos intentos policiales de controlar el tráfico de drogas y la economía informal en un barrio semi-autónomo hubieron de atenuarse notablemente tras tropezar los comportamientos policiales con objeciones judiciales y no lograr el programa concitar suficiente apoyo social (Balvig 2004; Jepsen 1996).

Por otro lado, las prohibiciones de acceso a lugares privados de acceso público suelen tropezar con barreras legales, como la necesidad de motivar la prohibición de entrada, en ejercicio del derecho de admisión, en centros comerciales. Aunque es una exigencia que no siempre se respeta (Mork Lomell, 2004).

Lo que predominan son técnicas indirectas de exclusión espacial, que dificultan las interacciones sociales con marginados y otros colectivos problemáticos en esos lugares. Se trata sobre todo de diseños urbanísticos disuasorios, como ausencia de bancos o aseos, o carácter incómodo de ellos, música de fondo a un volumen que molesta transcurrido cierto tiempo o que crea ambiente disuasorio, entre otros. Asimismo se producen desalojos por motivos comprensibles, como la limpieza diaria del espacio correspondiente, que se prolongan por periodos de tiempo exagerados; o se facilitan lugares alternativos de estancia de esos colectivos. También las técnicas de saturación antes aludidas, que hacen sentirse incómodos en parques u otros lugares públicos a esos colectivos (Borch, 2005; Doherty, Busch-Geertsema, Karpuskiene et al., 2008; Midtveit, 2005; National Council for Crime Prevention Finland, 2005).

\section{Conclusiones.}

La ciudad como lugar privilegiado de interacción social, abierta a relaciones entre todos los que habitan en ella, ofrece unas prometedoras posibilidades de autorrealización personal hace tiempo conocidas. Pero para ello la propia estructura ciudadana debe facilitar la relación con extraños, la interacción entre desconocidos en ella residentes. Sin embargo, es fácil apreciar cómo espacios cada vez más numerosos y amplios de las 
ciudades del mundo desarrollado se diseñan con el objetivo explícito o implícito de entorpecer una fluida interacción entre el conjunto de sus ciudadanos. La especialización de ciertas áreas para el consumo, el turismo o las actividades financieras, y la segregación de áreas residenciales según el nivel de renta, vienen acompañadas de una transformación de los lugares públicos y de los privados de acceso público. Estos pasan a ser en todo caso espacios vigilados estrechamente, además de incómodos en algunos casos, y de acceso restringido en otros, cuando no directamente privatizados.

Esa reorganización de las ciudades repercute, sin duda, sobre la ciudadanía en general, cuyas actividades en el ámbito público ciudadano se observan con sospecha, pero tiene como principal destinatario a determinados colectivos, cuya apariencia, forma de vida o escasa capacidad económica hace que su presencia sea indeseable en ciertos lugares públicos. Estos grupos, que suelen tener en mayor o menor medida problemas para su inclusión social, son desplazados de ciertos lugares porque su aspecto o comportamiento les otorga un estatus social incompatible con la imagen teatral e impostada que se quiere dar de ciertos espacios ciudadanos, o porque, simplemente, ciudadanos de ciertos niveles de renta no quieren relacionarse con quienes no alcanzan ese nivel. La idea, no siempre justificada, de que nos encontramos ante colectivos proclives a realizar conductas delictivas juega un papel secundario. Por lo demás, el incremento de la exclusión social de esos grupos que tales técnicas producen es fácilmente perceptible

En este estudio me he ocupado de tres fenómenos incursos en este emergente control de espacios públicos ciudadanos. El trabajo se inserta en una investigación más amplia que ya he descrito brevemente en páginas precedentes, de ahí que me haya ocupado de confrontar la difusión y empleo de las técnicas precedentes en Estados Unidos de América y los países nórdicos europeos.

Las urbanizaciones cerradas, muy extendidas en Estados Unidos, se han mostrado como un destacado instrumento de segregación social, mediante el cual los sectores acomodados de la sociedad se aíslan del resto de la sociedad, minimizando el contacto personal con quienes no responden a sus parámetros de nivel económico o extracción social o racial. Constituye una tecnología privatizadora de espacios y servicios públicos, que dificulta al conjunto de ciudadanos interactuar entres sí, generando exclusión social 
en unos y resentimiento en otros. Suponen una concepción de la ciudad, y de la sociedad en su conjunto, desprovista de objetivos comunes, mera yuxtaposición de colectivos separados entre sí.

Estas técnicas residenciales están mucho menos extendidas en los países nórdicos, donde, sin embargo, sí que han encontrado hueco los fenómenos de aburguesamiento de barrios. Estamos ante otra técnica espacial, más moderada, de exclusión social, que implica abandonar los esfuerzos por garantizar una composición interclasista de los barrios urbanos y por fomentar, consecuentemente, la integración ciudadana y social. La inicial expulsión por razones económicas de los colectivos sociales desfavorecidos hasta entonces residentes en esos barrios recuperados, viene luego acompañada por diferentes técnicas, generalmente de control social informal, que garantizan el mantenimiento de la homogeneidad social del barrio.

El uso de videocámaras en lugares públicos o privados de acceso público pretende restringir los comportamientos que se pueden realizar en las zonas urbanas sometidas a vigilancia. Mientras que la afección que producen en los derechos a la privacidad y a la libre disposición de datos personales está generalmente reconocida, sus efectos positivos sobre la prevención de conductas desordenadas o delictivas se han puesto fundadamente en duda. En cualquier caso, desde la perspectiva de la exclusión social, lo importante es que se han convertido en un instrumento privilegiado para impedir la estancia o el acceso a determinados lugares ciudadanos de aquellos colectivos que desentonan con los objetivos de selección de clientela, segregación social residencial y transformación teatral de los centros urbanos. Estamos hablando de marginados, sin techo, pobres y jóvenes, entre otros grupos.

En los países nórdicos el uso de videocámaras no está muy extendido, sobre todo en lugares públicos en sentido estricto. Rige en todos ellos un sistema de autorización previa por parte de organismos oficiales, con limitadas excepciones, y se debe informar de su localización, entre otras restricciones. Aunque su uso se está incrementando en algunos de estos países de forma notable, su empleo en lugares públicos está muy centrado en la prevención situacional de conductas delictivas, sin que el objetivo de excluir de manera generalizada a determinados colectivos de ciertos lugares se haya asentado. No se puede decir lo mismo de lugares privados de acceso público, donde las 
intervenciones amplían su foco a los colectivos marginados, por más que la limitada difusión de estas técnicas atenúe sus efectos negativos.

Lo más característico de la situación estadounidense es la escasa preocupación que existe sobre la legitimidad del uso de estas técnicas en lugares públicos o privados de acceso público para cualesquiera fines de control. Eso explica que no exista un marco normativo, federal o estatal, que aborde las implicaciones que su empleo tiene en derechos fundamentales como la privacidad o la protección de datos personales, ni que regule su uso. Consecuentemente, su instalación en lugares privados de acceso público está generalizada. Lo mismo ha comenzado a suceder con su instalación en lugares públicos en sentido estricto, algo retrasada hasta que los atentados de 2001 potenciaron su implantación.

Las prohibiciones de acceso o permanencia en determinados espacios públicos de ciertas clases de ciudadanos son técnicas en gran parte novedosas de control social. En lugar de prevenir o perseguir las conductas antisociales o delictivas, actuales o previsibles, de determinados individuos, se prefiere excluir de espacios de interacción ciudadana a colectivos enteros en función de su mera apariencia o forma de vida. Ese desplazamiento, que no precisa motivarse en términos preventivos, incide sobre un colectivo cada vez más numeroso de ciudadanos con problemas de inclusión social, fruto del incremento de las desigualdades sociales y de la anulación o reducción de las políticas sociales. De nuevo, saltan al primer plano intereses comerciales, financieros y de teatralización de los centros ciudadanos, junto al aburguesamiento de determinados barrios.

La expansión de estas técnicas en Estados Unidos está bien acreditada. Se extienden desde zonas urbanas de menudeo de droga y prostitución hasta parques públicos, zonas comerciales con sus aledaños y complejos de viviendas sociales, entre otros lugares. Las prohibiciones se estructuran como técnicas de carácter jurídico-mixto, administrativo y penal. Ello posibilita intervenciones iniciales sometidas a la mera discrecionalidad policial, mientras que la inobservancia de las restricciones entonces establecidas genera ya una infracción penal que conlleva la detención y prisión preventiva. Los espacios abarcados han crecido en extensión de tal modo que, no solo privan a los afectados de lugares imprescindibles para su socialización, sino que incluso les impiden el desplazamiento normal por el conjunto de la ciudad. 
Prácticas semejantes en los países nórdicos no han podido consolidarse hasta el momento. La limitada penetración del modelo de seguridad ciudadana en los últimos años, enfocado en la gestión de riesgos y la prevención situacional, no ha conseguido modificar sustancialmente la tradición nórdica de prevención del delito mediante intervenciones bienestaristas sobre los colectivos en riesgo de exclusión social. Resulta ilustrativo seguir la evolución de diversos intentos de implantación de estas técnicas y su progresiva transformación. Lo que sí han germinado son métodos indirectos de exclusión espacial mediante, por ejemplo, diseños urbanísticos disuasorios o técnicas de saturación.

En suma, la indudable transformación de nuestras ciudades en espacios cada vez más generadores de exclusión social no parece tener excepciones. Sin embargo, el análisis de regulaciones y prácticas llevado a cabo en dos ámbitos regionales diversos muestra cómo el progreso en esa dirección puede ser muy diferente a partir de las diferentes tradiciones de control social.

\section{Financiación}

El presente trabajo se ha beneficiado de una ayuda de la Dirección general de investigación científica y técnica del Gobierno de España, DER2012-30070 en la convocatoria de 2012.

\section{Referencias}

Anderson, D. (2012). The spy in the cab: the use and abuse of taxicab cameras in San Francisco. Surveillance and society, 10(2), 150-166.

Balvig, F. (2004). When law and order returned to Denmark. Journal of Scandinavian studies in criminology and crime prevention, 5, 167-187.

Baumann, Z. (2006). Modernidad líquida. Buenos Aires: Fondo de cultura económica.

Baumann, Z. (2007). Miedo líquido. Barcelona: Paidós.

Beckett, K. y Herbert, S. (2008). Dealing with disorder: social control in the postindustrial city. Theoretical Criminology, 12(1), 5-30. 
Beckett, K. y Herbert, S. (2010). Banished. The new social control in urban America. New York: Oxford University Press.

Björklund, F. (2013). Modernisation, balancing interests and citizen's rights. Public videosurveillance in Poland, Germany and Sweden. En F. Björklund, F. y Q. Svenonius (Eds.) Videosurveillance and social control in a comparative perspective: Routledge.

Borch, C. (2005). Crime prevention as totalitarian biopolitics. Journal of Scandinavian studies in criminology and crime prevention, 6, 91-105.

Cerezo Domínguez, A.I. y Díez Ripollés, J.L. (2011). Videocámaras y prevención de la delincuencia en lugares públicos. Análisis jurídico y criminológico. Valencia: Tirant-IAIC.

Coleman, R. y Sim, J. (2005). Contemporary statecraft and the punitive obsession: a critique of the new penology thesis. En J. Pratt, D. Brown, M. Brown, S. Hallsworth, y W. Morrison (Eds.), The new punitiveness. Trends, theories, perspectives. Portland: Willan Publishing.

Díez Ripollés, J.L. (2011). La dimensión inclusión / exclusión social como guía de la política criminal comparada. Revista electrónica de ciencia penal y criminología RECPC-.13-12: 1-36. Disponible en: http://criminet.ugr.es/recpc

Díez Ripollés, J.L. (2014). Sanciones adicionales a delincuentes y exdelincuentes. Contrastes entre Estados Unidos de América y países nórdicos europeos. Indret. En prensa.

Doherty, J., Busch-Geertsema, V., Karspuskiene, V., Korhonen, J., O’Sullivan, E., Sahlin, I., .... y Wygnánska, J. (2008). Homelessness and exclusion: regulating public space in European cities. Surveillance and society, 5 (3), 290-314.

Goldstein, E. (2003). Kept out: Responding to public housing no-trespass policies. Harvard Civil Rights-Civil Liberties Law Review, 38, 215-245.

Gras, M. (2004). The legal regulation of CCTV in Europe. Surveillance and society, 2 (2/3), 216-229.

Hempel, L y Töpfer, E. (2009). The surveillance consensus: reviewing the politics of CCTV in three European countries. European Journal of Criminology, 6(2), 157177.

Herbert, S. (2001). Policing the contemporary city. Fixing broken windows or shoring up neoliberalism? Theoretical Criminology, 5(4), 445-466.

v. Hofer, H. (2000). Die elektronische Überwachung von Straftätern in Schweden. En J.M. Jehle (Ed.), Täterbehandlung und neue Sanktionsformen. Kriminalpolitische Konzepte in Europa. Mönchengladbach: Forum Verlag Godesberg GmBH. 
Huey, L. (2010). False security or greater social inclusion?. Exploring perceptions of CCTV use in public and private spaces accessed by the homeless. British Journal of Sociology, 61(1), 63-82.

Jepsen, J. (1996). Copenhagen: a war on socially marginal people. En N. Dorn, J. Jepsen y E. Savona (Eds.), European drug policies and enforcement. New York: Mc Millan Press.

Lappi-Seppälä, T. (2014). Información personal.

Lohne, K. (2012). The Norwegian Data Inspectorate. Between governance and resistance. Surveillance and Society, 10(2), 182-197.

Loftsson, E, (2013). The pressure of the practice. Swedish public surveillance in an institutional perspective. En F. Björklund y Q. Svenonius (Eds.), Videosurveillance and social control in a comparative perspective. New York: Routledge.

Lynch, M. (2001-2002). From the punitive city to the gated community: security and segregation across the social and penal landscape. University of Miami Law Review, 56, 89-112.

Medina, J. (2011). Políticas y estrategias de prevención del delito y seguridad ciudadana. Montevideo: Editorial B de F.

Midtveit, E. (2005). Crime prevention and exclusion: from walls to opera music. Journal of Scandinavian studies in criminology and crime prevention, 6, 23-38.

Murakami Wood, D. (2009). The surveillance society: Questions of history, place and culture. Surveillance and Society, 6(2): 179-194.

National Council for Crime Prevention. Finland. (2005). The Bear Park godparents. Reclaiming a city park as the community's living room. En M. Shaw y K. Travers (Eds.) Urban Crime Prevention and Youth at Risk. Montreal. International Centre for the Prevention of Crime.

Norris, C., McCahill, M. y Wood, D. (2004). Editorial. The growth of CCTV: a global perspective on the international diffusion of video surveillance in publicly accessible space. Surveillance and society, 2 (2/3), 110-135.

Norris, C. y McCahill, M. (2006). CCTV: Beyond penal modernism. British Journal of Criminology, 46, 97-118.

Mork Lomell, H. (2004). Targeting the unwanted: Video surveillance and categorical exclusión in Oslo, Norway. Surveillance and society, 2 (2/3), 346-360. 
Rudinow Soetnan, A., Mork Lomell, H. y Wiecek, C. (2004). Controlling CCTV in public spaces: Is privacy the (only) issue?. Reflections on Norwegian and Danish observations. Surveillance and society, 2 (2/3): 396-414.

Simon, J. (2007). Governing through crime. New York: Oxford University Press.

Tham, H. (2001). Law and order as a leftist project?. Punishment and society. 3(3): 409426.

Torrönen, J. (2004). Zero tolerance, the media and a local community. Journal of Scandinavian Studies in Criminology and Crime Prevention, 5: 27-47.

Torrönen, J. y Korander, T. (2005). Preventive policing and security plans: The reception of new crime prevention strategies in three Finnish cities. Journal of Scandinavian Studies in Criminology and Crime Prevention, 6, 106-127.

Virta, S. (2013). Governing urban security in Finland: towards the 'European model' . European Journal of Criminology, 10 (3), 341-353.

Vozmediano, L. y San Juan, C. (2010). Criminología ambiental: ecología del delito y de la seguridad. Barcelona: UOC.

Welsh, B. y Farrington, D. (2009). Making public places safer. Surveillance and crime prevention. New York: Oxford University Press.

Young, J. (2003). La sociedad excluyente. Exclusión social, delito y diferencia en la modernidad tardía. Madrid: Marcial Pons.

José Luis Díez Ripollés es catedrático de derecho penal y director del Instituto Andaluz Interuniversitario de Criminología de la Universidad de Málaga. Sus más recientes líneas de investigación se concentran en la política criminal y en la política legislativa penal. Entre sus últimas publicaciones se encuentran (2013) Política criminal y derecho penal. $2^{\mathrm{a}}$ edic. Valencia. Tirant lo Blanch, y (2013) La racionalidad de las leyes penales, $2^{\mathrm{a}}$ edic. Madrid, Trotta. 